[Agr, Biol. Chem., Vol. 34, No. 9, p. 1301 1307, 1970]

\title{
Availability of Energy in Aliphatic Carboxylic Acids by Growing Chicks
}

\author{
By Minoru Yoshida, Hiroshi Morimoto* \\ and Ryohei ODA** \\ National Institute of Animal Industry, \\ * Japan Scientific Feeds Association, \\ **Faculty of Technology, Kyoto University \\ Received February 9, 1970
}

\begin{abstract}
Biological availability of 54 aliphatic acids was compared by mini-test with chicks. Availability of saturated fatty acids with carbon chain between 6 to 12 and of lactic, pyruvic, succinic, L-malic, fumaric and citric acid was satisfactory. Availability of fatty acids with carbon chain shorter than 6 and longer than 12, fatty acids with side-chain, except those of iso-type and unsaturated fatty acids was low. Availability of glycolic, DLglyceric, DL-malic, and maleic acid, and saturated dicarboxylic acids except succinic acid was also low. Digestibility of saturated fatty acids with carbon chain length longer than 8 decreased inversely with the increase of carbon chain length.
\end{abstract}

According to the statistics, " the demand for feed shown as total digestible nutrients increased linearly at the rate of 0.934 mega-ton per year during the recent 9 years from 9.15 mega-ton in 1959 to 17.06 mega-ton in 1967 , while the supply of feed of domestic origin including grass and roughage was increasing steadily but at much slower pace of 0.238 mega-ton per year. The statistics revealed that the trend of rapid increase in demand continued through 1968, and the trend is expected to continue in future.

Because of limited arable area in this country, rapid increase in domestic production of feed can not be expected in near future. Therefore, the large portion of feed supply has to depend upon the import from foreign countries. The statistics also revealed that

1) "Statistical Year Book on Concentrates," ed. by Livestock Bureau, Ministry of Agriculture and Forestry, Japan; "Pocket Statistics on Agriculture and Fishery," ed. by Agriculture and Forestry Economy Bureau, Ministry of Agriculture and Forestry, Japan. the amount of feed of foreign origin shown as total digestible nutrients would exceed the domestic production in 1970 . In other words, more than half of the supply of feed will come from overseas in 1970 and thereafter. This is really a serious problem for our agriculture as well as for our foreign trade.

With this background on the demand and and supply of feed specific in this country, a 3-year research project was initiated in 1967 to search for new energy sources for domestic animals and poultry under the cooperation of researchers in synthetic chemistry and animal nutrition. Development of the mini-test reported in the previous paper ${ }^{2 \prime}$ was very encouraging in the planning of the project. The chemicals able to replace the natural energy sources such as cereals may be too expensive at present, but the future progress in research on synthetic process and in massproduction will be effective to make the use

2) M. Yoshida and H. Morimoto, Agr. Biol. Chem., 34, 684 (1970). 
of the chemicals for feed feasible.

Among the 13 synthetic glycols tested in searching for energy sources for poultry feed which are to be supplied without cultivating the land or fishing in the water, 1, 2-propanediol and 1,3-butanediol were found to be utilzed by growing chicks as dietary energy sources. ${ }^{31}$ Rats also were reported to be able to utilize these two glycols. ${ }^{4,5}$

In this paper, the data on the availability of 54 aliphatic acids by growing chicks are presented as the first report of the cooperative 3-year research project, and the possibility of using these chemicals as energy sources in poultry feed is discussed.

\section{EXPERIMENTAL}

Test material. Among the materials reported in this paper, 6 dicarboxylic acids, adipic, pimelic, suberic, azelaic, sebasic and undecadionic acid, were synthesized in Oda's Laboratory, Kyoto University. Preparation of mixed acids was a byproduct of industrial production of adipic acid and contained $25 \%$ of succinic, $65 \%$ of glutaric and $10 \%$ of adipic acid. All of the other samples were obtained as reagent, whose grades were shown in Note in Tables I, II and III.

Gross energy of the test materials was determined by an automatic bomb calorimeter, CA-1 manufactured by Shimadzu Seisakusho. Gelatin capsule was used in the determination of volatile materials.

Bioassay. Procedure of the mini-test described in the previous paper ${ }^{2}$ was applied to the assays presented in this paper. In all of the assays, a linear dose-response curve was obtained for the growth responses of chicks in 6-day feeding of 3 standard diets of different energy levels, i.e. SO-0, SO-4 and SO-8 diet, of which composition was shown in the previous paper. ${ }^{2}$ The energy level of the test diet including $5 \%$ of a sample in place of cellulose in the standard

3) M. Yoshida, H. Hoshii and H. Morimoto, Japan Poultry Sci., 6, 73 (1969).

4) K. Ashida, private communication, (1968).

5) S. A. Miller and H. A. Dymsza, J. Nutr., 91, 79 (1967).
SO-0 diet was estimated, based on the growth response of the chicks on the diet, from this dose-response curve. In these dose-response curves $\mathrm{x}$-axis was adjusted as mentioned in the previous paper ${ }^{2)}$ so that the biologically available energy of the sample could be estimated directly.

Since formic and acetic acid are volatile and are expected to be lost from the diet as in the case of volatile alcohols reported previously, ${ }^{3)}$ they were infused directly into the crop of chicks as $10 \%$ aqueous solution. In this test, the same amount of SO-0 diet was fed to all of the chicks, and the standard dose-response curve was obtained from the growth response of chicks given $0,0.5$ and $1 \mathrm{ml}$ of soybean oil per head daily. ${ }^{2}$ Amount of soybean oil corresponding to the growth response of chicks on formic or acetic acid could be calculated from the standard curve, which was easily converted to available energy shown by kcal per $g$ of sample.

Two lots of 2 chicks each or of 4 chicks each were fed either standard or test diets in the standard procedure of mini-test in this Laboratory. However, the number of chicks in each lot was reduced depending on the amount of the sample available. Bioassay was repeated with the same sample if necessary. Total number of the chicks used for each test material was given in Tables I, II and III with experimental data.

In most of the tests, growth rate, feed intake and mortality of the chicks were recorded and, if necessary, a sample of excreta was collected to determine the digestibility of the sample as mentioned later. To compare the difference in palatability of the samples tested at different times, average feed intake of the test diet was shown by a ratio of the intake to that of the standard SO-4 diet as palatability index, in which the intake of SO-4 diet was taken as 100 .

Appropriateness of the test material to be used as poultry feed was judged mainly on the availability of energy, i. e. ratio of available energy to gross energy; mortality; palatability; and digestibility.

Determination of digestibility. When the determination of digestibility was necessary, chromic oxide at $0.05 \%$ level was mixed in all of the standard and test diets before feeding to the chicks and the excreta of the chicks were collected for the last 2 days of mini-test. Contents of crude fat and chromic oxide in the diets and excreta were determined by ether extraction with Soxhlet apparatus and with phosphate 
reagent, ${ }^{6}$ respectively. True digestibility of the test material was calculated as follows:

$$
\begin{aligned}
D C= & 100-\left(F F_{T} \times D C_{T} / F C_{T}\right. \\
& \left.-F F_{S} \times D C_{S} / F C_{S}\right) /\left(D F_{T}-D F_{S}\right) \times 100
\end{aligned}
$$

where, $D C$ : digestibility coefficient $(\%)$

$F F_{T}$ : fecal crude fat on test $\operatorname{diet}(\%)$

$F C_{T}$ : fecal chromic oxide on test diet $(\%)$

$D F_{T}$ : dietary crude fat of test diet $(\%)$

$D C_{T}$ : dietary chromic oxide of test diet $(\%)$

$F F_{S}$ : fecal crude fat on SO-0 diet $(0,6)$

$F C_{S}$ : fecal chromic oxide on $\mathrm{SO}-0$ diet $(\%)$

$D F_{S}$ : dietary crude fat of SO-0 diet (\%)
$D C_{S}$ : dietary chromic oxide of SO-0 diet $(\%)$

This procedure was only applicable to the test materials soluble in ethyl ether.

\section{RESULTS AND DISGUSSION}

It should be pointed out before dicussing the data obtained in these mini-tests, that the procedure was devised to be suitable to estimate biological availability of small amounts of samples, i.e. 5 to $50 \mathrm{~g}$, sacrificing the length of feeding period and the number of chicks,

Table I. Gross Energy, Avallability, Palatability and Digestibility

\begin{tabular}{|c|c|c|c|c|c|c|c|c|}
\hline Sample & & $\begin{array}{l}\text { No. of } \\
\text { chicks }\end{array}$ & $\begin{array}{c}\text { Gross } \\
\text { energy } \\
\text { kcal/g }\end{array}$ & $\begin{array}{l}\text { Avail- } \\
\text { able } \\
\text { energy } \\
\mathrm{kcal} / \mathrm{g}\end{array}$ & $\begin{array}{c}\text { Availa- } \\
\text { bility } \\
\text { AE/GE } \\
\%\end{array}$ & $\begin{array}{l}\text { Palata- } \\
\text { bility } \\
\text { index }\end{array}$ & $\begin{array}{c}\text { Digesti- } \\
\text { bility } \\
\text { coeff. } \\
9_{0}^{\circ}\end{array}$ & Note \\
\hline Formic & $\mathrm{C}_{1}$ & $4 / 4^{b 1}$ & - & $x^{01}$ & - & 30 & & Speciald! \\
\hline Acetic & $\mathrm{C}_{2}$ & $1 / 4$ & 3.15 & 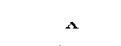 & - & 35 & & $"$ \\
\hline Propionic & $\mathrm{C}_{3}$ & 4 & 4.79 & -6.4 & - & 57 & & $"$ \\
\hline$n$-Butyric & $\mathrm{C}_{4}$ & 4 & 5.80 & -19.4 & - & 44 & & First $\left.{ }^{d}\right)$ \\
\hline$i$-Butyric & $\mathrm{C}_{4}$ & 4 & 5.78 & 3.5 & 61 & 80 & & Special \\
\hline$n$-Valeric & $\mathrm{C}_{5}$ & 12 & 6.53 & 0.8 & 13 & 68 & & First \\
\hline$i$-Valeric & $\mathrm{C}_{5}$ & 12 & 6.45 & -6.3 & - & 71 & & Special \\
\hline Pivalic & $\mathrm{C}_{5}$ & 2 & 6.61 & -22.6 & - & 57 & & $\mathrm{BDH}^{(1)}$ \\
\hline n-Caproic & $\mathrm{C}_{\hat{6}}$ & 12 & 7.36 & 5.0 & 68 & 79 & & First \\
\hline i-Caproic & $\mathrm{C}_{6}$ & 12 & 7.15 & 5.0 & 70 & 81 & & Reagent ${ }^{d l}$ \\
\hline n-Heptoic & $\mathrm{C}_{7}$ & 12 & 7.59 & 6.9 & 90 & 73 & & $\mathrm{BDH}$ \\
\hline n-Caprylic & $\mathrm{C}_{8}$ & 20 & 7.99 & 3.1 & 39 & 69 & 100 & Special \\
\hline 2-Et-Hexanoic & $\mathrm{C}_{8}$ & $1 / 4$ & 7.97 & $\therefore$ & - & 13 & & First \\
\hline n-Nonanoic & $\mathrm{C}_{9}$ & 9 & 8.16 & 6.8 & 84 & 65 & 97 & $\mathrm{BDH}$ \\
\hline n-Capric & $\mathrm{C}_{10}$ & 4 & 8.48 & 9.1 & 107 & 52 & 94 & First \\
\hline$n$-Undecanoic & $\mathrm{C}_{11}$ & 2 & 8.55 & 8.0 & 94 & 72 & & Special \\
\hline Lauric & $\mathrm{C}_{12}$ & 4 & 8.75 & 9.2 & 105 & 81 & 83 & Reagent \\
\hline Myristic & $\mathrm{C}_{14}$ & 4 & 9.13 & 3.0 & 33 & 104 & 37 & Special \\
\hline Palmitic & $\mathrm{C}_{16}$ & 4 & 9.30 & 1.4 & 15 & 105 & 34 & " \\
\hline Stearic & $\mathrm{C}_{18}$ & 4 & 9.45 & 0 & 0 & 106 & 38 & " \\
\hline Behenic & $\mathrm{C}_{22}$ & 4 & 9.73 & -5.1 & - & 100 & & Reagent \\
\hline
\end{tabular}
OF SATURATED FatTy ACIDS

a) See text.

(b) Dead/total

c) Can not be estimated because chicks died.

d) Special: special grade reagent; First: first grade reagent; Reagent: reagent; BDH: obtained from the British Drug Houses Ltd.

6) M. Yoshida, K. Kosaka, S. Horii and K. Kameoka, Japan. Poultry Sci., 4, 24 (1967). 
therefore, the accuracy of the conclusion. ${ }^{2}$ The mini-test is certainly a useful tool for evaluating a sample for screening purpose, in other words, for judging whether or not the sample is hopeful as dietary energy source for poultry. Therefore, it is most necessary to confirm the conclusion of the mini-test by long term feeding experiments with a large number of chicks.

The data of the mini-tests on saturated fatty acids were summarized in Table I.

It was unexpected that chicks could not utilize energy in most of the volatile fatty acids with carbon chain shorter than 5, which are known to be produced in rumen and readily utilized as energy source by ruminants. Since acetic acid, as well as formic acid, was infused in crop directly as $10 \%$ aqueous solution, ${ }^{2)}$ physical and chemical properties, such as $\mathrm{pH}$, may have physiologically detrimental influence and may lower the growth rate as well as palatability of the diet. On the other hand, propionic and butyric acid were mixed into feed and fed to chicks. Low palatability of these acids may suggest that physical and chemical natures, such as strong offensive smell or acidity of the samples make the chicks lose appetite, resulting in slow growth rate. However, growth retardation of the chicks shown by negative value of available energy seemed to be too severe to be explained by small appetite, since the effect of difference in feed intake on the available energy was mostly cancelled out by taking body weight gain per $100 \mathrm{~g}$ feed instead of body weight gain itself in these mini-tests. Further studies are certainly necessary to confirm whether chicks can actually utilize volatile fatty acids or not, and to show the reason why they do not if it is confirmed that chicks have no ability to utilize volatile fatty acids. Availability of iso-butyric acid by chicks seemed to be higher than that of the other volatile fatty acids. The observation should be confirmed in further studies.

Ozaki's old work $^{71}$ revealed that rats on the diets containing $10 \%$ of acetic, butyric, caprylic and capric acid died within 40 days of experimental period, although his experimental diet may have been too simple from the present knowledge of rat nutrition. Ashida ${ }^{81}$ found that growth rate of rat on $5 \%$ acetic, propionic and valeric acid was satisfactory, although none of them exceeded the growth rate of the control rats. Those findings on both rats and chicks suggest that some problems have been left over in the attempt to utilize volatile fatty acids as feedstuff for energy source.

Fatty acids of odd numbers of carbon chain: heptoic, nonanoic, and undecanoic acids, all of which are not natural, were available by the chicks as efficiently as the natural even number fatty acids. The data may encourage us to study further the possibility of using synthetic fatty acids for feed, which may be a mixture of fatty acids of odd and even numbers of carbon.

The data on pimelic and 2-ethyl-hexanoic acid suggested that chicks could not utilize fatty acids with side chain, except that of iso-type, i.e. single methyl branch at the opposite end of carbon chain to the carboxyl group. The findings may give severe restriction to the expectation in using synthetic fatty acids as feed, since such acids should be composed of only normal and iso-type acids.

Chicks could utilize free fatty acids with carbon chain length between 6 to 12, but it should be pointed out that the palatability of these acids was as low as less than 81 , and at the same time specific offensive smell of these acids should be kept in mind since it is certainly unpleasant to handle the acids as feedstuff.

Availability of energy in fatty acids of carbon chain length longer than 14 is lowered with the increase in chain length as shown in

7) J. Ozaki, Nippon Nôgeikagaku Kaishi, 8, 1286 (1932).

8) K. Ashida, private communication (1969). 
Table I. Low availability of these fatty acids is mainly due to low digestibility as shown in the column of digestibility coefficient in Table I. Palatability index higher than 100 by 4 to 6 on these fatty acids indicated that chicks took 4 to $6 \%$ more feed which contained $5 \%$ of an undigestible, consequently inert fatty acid than the control SO-4 diet. The findings agree with those reported by Renner and Hill, ${ }^{2)}$ who studied the utilization of free fatty acids of carbon chain length between 12 to 18 . They observed that absorbability of saturated fatty acids by both growing chicks and laying hen decreased with the increase in carbon chain length, while the absorbability of oleic acid was satisfactorily high. They also reported low palatability of lauric acid and suggested that lauric acid might have some irritating effect on the gastro-intestinal tract of chicks. This irritating effect may not be specific to lauric acid, but the effect seems to be rather common to the free saturated fatty acids of carbon chain length from 3 to 12 as shown by the palatability index in Table I.

The data on unsaturated, hydroxy and keto acids were summarized in Table II.

Though no chick died on glycolic acid as shown in Table II the chicks took feed at the level of only $32 \%$ of the amount taken by chicks on the standard SO-4 diet, and they lost body weight. Availability and palatability of lactic acid were satisfactorily close to those expected from the biochemical glycogenic function. Availability of energy in pyruvic acid was also satisfactory, although paratability was somewhat low and the acid gave offensive smell to the diet. On the other hand, availability of DL-glyceric acid, D-form of which is a constituent of anaerobic muscle glycolysis, was unexpectedly low. Antagonistic effect of $\mathrm{L}$-form to the utilization of $\mathrm{D}$ form may be one of the possible explanation of low availability.

Table II. Gross Energy, Availability and Palatability oF Unsaturated, Hydroxy and Keto ACIDS

\begin{tabular}{|c|c|c|c|c|c|c|c|}
\hline Sample & & $\begin{array}{l}\text { No, of } \\
\text { chicks }\end{array}$ & $\begin{array}{l}\text { Gross } \\
\text { energy } \\
\text { kcal } / \mathrm{g}\end{array}$ & $\begin{array}{l}\text { Available } \\
\text { energy } \\
\mathrm{kcal} / \mathrm{g}\end{array}$ & $\begin{array}{c}\text { Availability } \\
\mathrm{AE} / \mathrm{GE} \\
6\end{array}$ & $\begin{array}{c}\text { Palatability } \\
\text { indexal }\end{array}$ & Note ${ }^{a 1}$ \\
\hline Glycolic & $\mathrm{C}_{2}$ & 4 & 2.18 & $-{ }^{b i}$ & - & 32 & Reagent \\
\hline Lactic & $\mathrm{C}_{3}$ & 8 & 3.23 & 2.4 & 76 & 97 & Special \\
\hline DL-Glyceric & $\mathrm{C}_{3}$ & 2 & 2.87 & 0.1 & 3 & 86 & Reagent \\
\hline Pyruvic & $\mathrm{C}_{3}$ & 8 & 3.06 & 3.8 & 123 & 88 & Special \\
\hline Acrylic & $\mathrm{C}_{3}$ & $\left.2 / 4^{a}\right)$ & 3.68 & $\mathrm{x}^{a, 1}$ & - & 22 & Special \\
\hline Methacrylic & $\mathrm{C}_{4}$ & 4 & 5.39 & -37.6 & - & 46 & Reagent \\
\hline Crotonic & $\mathrm{C}_{4}$ & 4 & & -33.4 & - & 41 & Reagent \\
\hline Sorbic & $\mathrm{C}_{6}$ & 4 & 6.58 & 3.2 & 50 & 66 & Special \\
\hline Gluconic & $\mathrm{C}_{6}$ & & 1.69 & -2.3 & - & 98 & $\begin{array}{l}\text { Reagent } \\
50 \% \text { solution }\end{array}$ \\
\hline Undecylenic & $\mathrm{C}_{11}$ & 2 & 8.31 & -5.4 & - & 52 & Reagent \\
\hline Elaidic & $\mathrm{C}_{18}$ & 4 & 9.27 & -5.7 & - & 78 & $\mathrm{BDH}$ \\
\hline Linoleic & $\mathrm{C}_{18}$ & 4 & 9.32 & -19.8 & - & 54 & Reagent \\
\hline Linolenic & $\mathrm{C}_{18}$ & I & 9.12 & -37.0 & - & 20 & Special \\
\hline
\end{tabular}

a) See footnotes of Table I.

b) Chicks lose body weight.

9) R. Renner and F. W. Hill, J. Nutr., 74, 259 (1961). 
TABle III. Gross Energy, Avallability and Palatability OF DI-, TRI-CARBOXYLIC ACIDS

\begin{tabular}{|c|c|c|c|c|c|c|c|}
\hline Sample & & $\begin{array}{l}\text { No. of } \\
\text { chicks }\end{array}$ & $\begin{array}{l}\text { Gross } \\
\text { energy } \\
\mathrm{kcal} / \mathrm{g}\end{array}$ & $\begin{array}{c}\text { Available } \\
\text { energy } \\
\mathrm{kcal} / \mathrm{g}\end{array}$ & $\begin{array}{c}\text { Availability } \\
\text { AE/GE } \\
\%\end{array}$ & $\begin{array}{c}\text { Palatability } \\
\text { index }\end{array}$ & Note \\
\hline Malonic & $\mathrm{C}_{3}$ & 4 & 1.94 & -12.5 & - & 66 & Special \\
\hline Succinic & $\mathrm{C}_{4}$ & 12 & 2.99 & $5, I$ & 173 & 90 & $"$ \\
\hline DL-Malic & $\mathrm{C}_{4}$ & 4 & 2.37 & -8.9 & - & 61 & " \\
\hline L-Malic & $\mathrm{C}_{4}$ & 4 & 2.44 & 6.4 & 262 & 47 & Reagent \\
\hline Tartaric & $\mathrm{C}_{4}$ & 4 & 1.85 & 0.9 & 49 & 77 & Special \\
\hline Maleic & $\mathrm{C}_{4}$ & $4 / 4^{a}$ & 2.77 & $x^{a)}$ & - & 7 & " \\
\hline Fumaric & $\mathrm{C}_{4}$ & 4 & 2.78 & 5.1 & 183 & 82 & $"$ \\
\hline Oxalacetic & $\mathrm{C}_{4}$ & 4 & 2.08 & -9.4 & - & 41 & $\mathrm{BDH}$ \\
\hline Glutaric & $\mathrm{C}_{5}$ & $2 / 4$ & 3.90 & 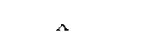 & - & 11 & Special \\
\hline$\alpha-$ Ketoglutaric & $\mathrm{C}_{5}$ & 4 & 2.90 & -4.8 & - & 37 & " \\
\hline Itaconic & $\mathrm{C}_{5}$ & $1 / 4$ & 3.58 & $s$ & - & 20 & Reagent \\
\hline Adipic & $\mathrm{C}_{6}$ & 4 & 4.50 & -35.3 & - & 52 & (b) \\
\hline Citric & $\mathrm{C}_{6}$ & 4 & 2.21 & 2.1 & 95 & 86 & Special \\
\hline cis-Aconitic & $\mathrm{C}_{6}$ & 4 & 2.89 & -15.1 & - & 27 & Reagent \\
\hline Pimelic & $C_{7}$ & 1 & $4.8 \mathrm{I}$ & -16.2 & - & 87 & 6) \\
\hline Suberic & $\mathrm{C}_{8}$ & 4 & 5.59 & -16.0 & - & 62 & b) \\
\hline Azelaic & $\mathrm{C}_{9}$ & 4 & 5.93 & -01 & - & 34 & b) \\
\hline Sebacic & $\mathrm{C}_{10}$ & 1 & & -32.6 & - & 73 & b) \\
\hline Undecadioic & $\mathrm{C}_{11}$ & 2 & 6.66 & -14.7 & - & 49 & b) \\
\hline Mixed acids ${ }^{d}$ & & 8 & 3.89 & 0.7 & 18 & 60 & \\
\hline
\end{tabular}

a) See footnotes of Table I.

b) See text.

c) See footnote 2 of Table II.

d) Contained $25 \%$ of succinic acid, $65 \%$ of glutaric acid and $10 \%$ of adipic acid.

All of the unsaturated acid, except sorbic acid, depressed growth of chicks as shown by negative available energy in Table II. Rancidity of these acids may be one of the reasons of ill effect. Acrylic acid was fatal to the chicks.

The data on di- and tri-carboxylic acids were summarized in Table III. Among the di- and tri-carboxylic acids tested, succinic acid, L-malic acid, fumaric acid and citric acid were readily available by the chicks, although their palatability was not quite satisfactory, being less than $90 \%$ of feed taken by chicks on the standard SO-4 diet. It should be pointed out that all of these acids are the constituent elements of the tricarboxylic acid cycle in aerobic metabolism of carbohydrate. On maleic acid, the isomer of fumaric acid, chicks took only $6 \mathrm{~g}$ of diet at the beginning of the experiment, when they were starved, and all of them died within two days. Chicks can be alive as long as 6 days even under the conditions of losing body weight, as in the case of feeding glycolic acid shown in Table II and azelaic acid shown in Table III. No group of chicks except those fed maleic acid died within 2 days on various poisonous materials shown in Tables I, II and III. These observations indicated that maleic acid worked out as a strong poison. It is expected that maleic acid, as an antagonist of fumaric acid, breaks down the tri-carboxylic acid cycle and cuts off the supply of biologically available energy from 
carbohydrate. Unexpectedly strong detrimental effect of malonic acid, and especially of glutaric acid might be explained by the antagonistic effect of these acids to those related to the tricarboxylic acid cycle of aerobic metabolism of carbohydrate. Detrimental effect of DL-malic acid was also suspected to be due to the antagonistic effect of D-isomer, as in the case of DL-glyceric acid.

Rats were also found to utilize fumaric acid efficiently, but they lost body weight severely on maleic acid. ${ }^{8}$ Availability of the saturated dicarboxylic acids of carbon number from 3 to 11 , except 4 , i.e. succinic acid, was also very low according to Ashida's data ${ }^{8}$ on rats. Ozaki ${ }^{10)}$ also found that rats on azelaic acid grew slowly and their body weight was decreased in the latter half of feeding period of about 30 days.

Negative availability of oxalacetic acid, $\alpha$ ketoglutaric acid and cis-aconitic acid, all of which are the constituents of tricarboxylic acid cycle, were unexpected. However, it should be kept in mind that these acids were given to chicks orally as a mixture with other dietary ingredients, including protein and minerals. Therefore, some chemical change may have possibly taken place in the diet which decomposed the acids themselves or other dietary nutrients possibly producing detrimental substances in the diet. Different results will be obtained if these acids be given with some protecting means, or given separately from the other dietary ingredients.

Growth depression and death of chicks on

10) J. Ozaki, Nippon Nogeikagaku Kaishi, 3, 977 $(1927)$. itaconic acid, i.e. ethylenesuccinic acid, may suggest either that the acid works as an antagonist of succinic acid or the related compounds disturbing the tricarboxylic acid cycle as in the case of maleic acid and glutaric acid, or that the acid becomes rancid in the diet as in the case of unsaturated fatty acid shown in Table II. It should be pointed out that the chemical structure of itaconic acid, i.e. ethylenesuccinic acid, is related to that of acrylic acid, which is ethyleneacetic acid, and of metacrylic acid, which is ethylenepropionic acid. Acrylic acid was toxic and metacrylic acid depressed growth rate as shown in Table II.

Dibasic acids of carbon chain longer than 6 were all unavailable for chicks. Enzymic system to utilize energy of these dibasic acids seemed to be lacking in chicks' body. Rats also were unable to utilize these acids. Since these dibasic acids are crystal and, therefore, readily mixed in the poultry feed which is served as mash, great expectation was given to these acids. However, chicks dislike these dibasic acids as shown by low palatability index and can not utilize energy of these acids efficiently. As for succinic acid, only one hopeful energy source among dibasic acids tested, its relatively low energy level, $2.99 \mathrm{kcal} / \mathrm{g}$, may be a weak point for future use of this acid as dietary energy source economically in large scale.

Mixed acids shown in Table III were a byproduct of industrial production of adipic acid, of which low availability certainly corresponded to the low availability of glutaric acid, the major constituent of this mixed acids. 